\title{
Treatment of the Effluent G enerated from the Pickling M ethod and to remove their Toxic Property to make it Eco-friendly
}

\author{
Rajeshwari Chatterjee*
}

\section{A bstract}

Pickling is one of the effective processes of Cold Rolled Coil processing. The theory of pickling is based upon acid wash treatment by 6 to $8 \%$ of hydrochloric acid $(\mathrm{HCl})$ to remove the iron scales from the coils. As the result $\mathrm{Fe}^{+2}$, $\mathrm{Fe}^{+3}$ iron salts $\&$ acid are liberated as effluents. Those effluents need a proper treatment to remove their toxic properties \& make them eco-environment friendly. In this industry the effluent is treated with a large effluent treatment plant where acid and iron is removed satisfactorily. After the treatment acid part is evaluated by the help of $\mathrm{pH}$ meter resulting generally 6 to 8 range which follow the National Institute for Occupational Safety and Health but due to some methodological problems iron part is not evaluated which need an efficient system. The major objective of this theme is to make the monitoring $\&$ remove the remaining iron part in the ultimate water, which is discharged after effluent treatment, \& resulting an efficient regeneration $\&$ reuse of that water. In the present paper case study has been conducted where this pickling method is used in Tata Ryerson, which is a joint venture between Tata Steel \& Ryerson Tull, USA. It has a state-of-the art Cold Rolled

*Department of HMCT, BIT, Mesra, Ranchi; rajch_2001@yahoo.com 
coil processing line in Bara, Jamshedpur. The coils are cut to lengths as per requirements \& packed in wooden crates for dispatch to various locations. The machine at Tata Ryerson has facilities like eleven roll levelers that are capable of providing dead flat surfaces(10 I Units) with close tolerances $(H-1 \mathrm{~mm}$.) on the length.

Keywords: effluent, acids, eco-environment, $\mathrm{HCl}$, pickling.

\section{Introduction}

Before electroplating the metal surface has to be clean. Various acids such as $\mathrm{HCl}, \mathrm{HNO}_{3}$ or $\mathrm{H}_{2} \mathrm{SO}_{4}$ are used for this purpose as picking liquors to remove surface oxides. The spent liquors contain residual acid and appropriate salts. Their compositions depend on the treated metal objects. Very often they contain very harmful heavy metals. The components from spent liquor must be removed, recovered or recycled for the environmental reasons. A neutralization procedure, used traditionally for the effluents treatment, is not always sufficient for their purification. From the viewpoint of both the environmental protection and economy, pollutants should be removed, whereas valuable materials can be recovered. The different techniques have been developed in order to purify wastewater from the iron and steel industry and to recover the components. The membrane techniques play a particular role in the effluent treatments. Electro dialysis was proposed for the recovery of hydrochloric or sulfuric acid (Urano, Nato, 1984). The same method was investigated for the recovery of the acids from rinsing water after metal etching (Wis 'niewski, 1997). From an economical point of view, the benefits arise from the acid recycling, as well as, from reduced consumption of alkali required for the neutralization process. The ion exchange method (Dobrevsky, Dimova-Todorova, Panayotova, 1996), as well as, integration of electro dialysis with ion exchange allows recovering pure water from etching effluents, which can be reused for rinsing of high-quality steel after etching (Wis'niewski, Suder, 1995). Moreover, the electroplating rinse solutions contain significant amounts of valuable or toxic metal ions, which may be separated by Donnan dialysis (Wo' dzki, Sionkowski, Hudzik-Pieta, 1996), or using a liquid membrane (Guha, Yun, Basu, Sirkar, 1994). Reverse 
osmosis was also applied for the concentration and separation of electroplating wastewater(Scott,1997, Chai, Chen, Lock Yue, etal, 1997 ).

Pickling processing is a process through which scales $\&$ iron oxide residue on the hot rolled strip coils are removed. Mainly on the hot rolled strip coils three types of iron oxide layers is observed a) Ferric oxide $\left(\mathrm{Fe}_{2} \mathrm{O}_{3}\right)$ Upper Hardest Layer b). Ferrosoferric oxide $\left(\mathrm{Fe}_{3} \mathrm{O}_{4}\right)$ c) Ferrous Oxide (FeO) Lower Most Layer.

By removing the scales and oxide layers from the surface of hot rolled strip coils it has become suitable for Cold Rolling. As the oxide layers and scales are harder than base metal, therefore it is necessary to remove these oxides and scales for further processing.

A pickling line for steel strip is made up of pay off equipment, tension control equipment, strip centering devices, hydrochloric acid bath, water cleaning bath, hot blast drying \& reels to rewinding the strips treated. In addition, pickling lines are also equipped with acid regeneration or wasted acid recycle system. The pickling line is used to prepare clean input materials for the consequent cold rolling steel strip production.

\section{Objective}

- In the continuous pickling line $\&$ push pull-pickling line the strip is freed from scale $\&$ oxide layers while passing through an acid bath.

- To separate out the layers and make the strips free from surface defects.

- To reduce the thickness \& make it uniform.

- To check the damage of surfaces of the strips during rolling \& rolling cycle can be reduced.

\section{Chemical Reactions}

Chemical reactions in Pickling tanks are as follows:

1. $2 \mathrm{Fe}_{2} \mathrm{O}_{3}+8 \mathrm{HCl}$

$4 \mathrm{FeCl}_{2}+\mathrm{O}_{2}+4 \mathrm{H}_{2} \mathrm{O}$ 
M apana J Sci, 10, 1(2011) Treament of theEffluent Generded from thePidklingMethod

2. $\mathrm{Fe}_{2} \mathrm{O}_{3}+6 \mathrm{HCl} \longrightarrow 2 \mathrm{FeCl}_{3}+3 \mathrm{H}_{2} \mathrm{O}$

3. $\mathrm{Fe}_{3} \mathrm{O}_{4}+8 \mathrm{HCl} \longrightarrow \mathrm{FeCl}_{2}+2 \mathrm{FeCl}_{3}+4 \mathrm{H}_{2} \mathrm{O}$

4. $\mathrm{FeO}+2 \mathrm{HCl} \longrightarrow \mathrm{FeCl}_{2}+\mathrm{H}_{2} \mathrm{O}$

\section{Preference of $\mathrm{HCl}$ over $\mathrm{H}_{2} \mathrm{SO}_{4}$ (Reasons)}

1. $\mathrm{HCl}$ is cheaper as compared to $\mathrm{H}_{2} \mathrm{SO}_{4}$ and its handling is also safe.

2. $\mathrm{HCl}$ is easily available as compared to $\mathrm{H}_{2} \mathrm{SO}_{4}$.

3. $\mathrm{HCl}$ shows inertness to base metal (reacts only with oxides and scales) but $\mathrm{H}_{2} \mathrm{SO}_{4}$ reacts with metallic iron \& producing some insoluble precipitations of metallic sulphate $\&$ ultimately the overall reaction is checked.

4. The Regeneration of $\mathrm{HCl}$ is easy as compared to $\mathrm{H}_{2} \mathrm{SO}_{4}$.

5. When $\mathrm{HCl}$ is used Oxygen comes out to atmosphere.

\section{Materials \& M ethods}

\section{Pickling line processing}

Pickling line process deals with several components. Their functions are represented respectively as follows:

a. Entry coil car- Its main function is to lift the coils from the coil storage and load it on to the uncoiler mandrel. The hydraulic cylinder lifts the coil. The movement of the coil car is governed the hydraulic motor and chain mechanism.

b. Uncoiler - Its main function is to uncoil the given Mother Coil, which is fed to its mandrel. By doing this it provide coil to other components for processing. It consists of phosphor bronze wedge, which helps, in its expansion and collapse.

c. Peelar table -It supports the opening of the coils and serves as directing table between uncoiler and grinder.

d. Guides - Guides provide direction to coil coming from uncoiler, it also gives direction to the coil for further processing. 
e. Hydraulic shear - It helps in flattening the coil coming from mother coil.

f. Clamp - It is used to fix the sideways movement according to the width of processing coil.

g. Loop pit - Speed of uncoiler mandrel and recoiler mandrel are different. Due to this the length of coil uncoiled from uncoiler is different to that of the length of coil recoiled on recoiler. Due to these phenomena there is al ways some extra portion of coil in line, for proper working of components and proper passing of the coil through the line Loop Pit is provided in which extra parts are hung.

h. Winch drum - Winch drum are provided to give the forward motion of incoming coil from uncoiler.

i. Acid pickling tank - There is pickling tank in the pickling line. A mong tanks available in pickling line i.e. clod water tank, hot water tank and pickling tank, pickling tank is largest than others. The temperature of pickling tank should be maintained between 50 to $90^{\circ} \mathrm{C}$. Concentration of acid in pickling tank should also be between $6 \%$ to $18 \%$ and FE content should also be less than 190 $\mathrm{gm} /$ liter.

The chemical reactions taking place in the pickling tanks are as follows:

- $2 \mathrm{Fe}_{2} \mathrm{O}_{3}+8 \mathrm{HCl} \rightarrow 4 \mathrm{FeCL}_{2}+4 \mathrm{H}_{2} \mathrm{O}+\mathrm{O}_{2}$

- $\mathrm{Fe}_{2} \mathrm{O}_{3}+6 \mathrm{HCl} \rightarrow 2 \mathrm{FeCL}_{3}+3 \mathrm{H}_{2} \mathrm{O}$

- $\mathrm{FeO}+2 \mathrm{HCl} \rightarrow \mathrm{FeCL} 2+\mathrm{H}_{2} \mathrm{O}$

- $\mathrm{Fe}_{3} \mathrm{O}_{4}+8 \mathrm{HCl} \rightarrow \mathrm{FeCL}_{2}+2 \mathrm{FeCL}_{3}+4 \mathrm{H}_{2} \mathrm{O}$

There are provided acid circulation pump for proper circulation of acid inside the pickling tank.

j. A cid tank - To charge the pickling tank with acid there is an acid tank, which stores fresh acid and discharge to pickling tank whenever there is need. Size- 40500 × 730 × 780mm (L*W*Depth)

k. Scrubber unit:- To protect the various steel structures and equipments from the $\mathrm{HCL}$ fumes coming out from pickling tank a 
fume exhaust system is available in the pickling tank called SCRUBBER. It absorbs acidic fumes generated during pickling process. Fumes are condensed by flowing water on fumes and get acid with low strength compared to acid in acid tank.

I. Scrubber tank - Acid formed by the acidic fumes and water is stored in Scrubber tank, whenever there is need of acid in pickling tank then from this Scrubber tank we provide acid to pickling tank.

m. Chimney - Chimney is provided to exhaust the gasses coming out of scrubber tank as a result of reaction between acidic fume and water.

n. Impeller - Gasses coming out from scrubber tank as a result of reaction between acidic fumes and water is danger for human being. So its safe discharge is necessary to accomplish that task we give Impeller before the chimney to discharge it at appropriate height.

o. Cold water rinse tank - Cold-water rinse tank is given to wash away the acid stains formed in pickling tank. It is provided with proper spray system with appropriateno. of nozzles.

p. H ot water rinse tank - If any stains remain after cold water rinse tank. Then it is removed by hot water rinse tank. It is also provided with proper spray system with appropriate no. of nozzles so that circulation of hot water takes place properly. The temperature of hot water rinse tank should be maintained between 50 - 90 deg. Celsius.

q. Pinch rolls - Its function is to squeeze out fluid (water) from sheet in line run and to push the sheet for further processing.

r. H ot air blower- Its function is to dry out the coils completely with the help of hot steam under pressure. The range of temperature is from 80 to $110^{\circ} \mathrm{C}$

S. R.P. oil tank - There is given a layer of R.P. oil to prevent the formation of further oxide. Layer of R.P. oil prevent the coil direct contact from atmosphere.

t. Oiler rolls - Oiler rolls are provided to give the layer of it on the pickled coil. 
u. Hydraulic shear - After getting desired outer diameter of pickled coil we need to cut it, for that hydraulic shear is given with cutter.

v. Pressure pad unit - It is used to provide some tension to the pickled coils for their proper and tight rewinding.

w. Deflector roll - It diverts the pickled coils towards the recoiler.

x. Recoiler: It is used to rewind the pickled coils. The recoiler mandrel may be in various shapes - conical, cylindrical, or stepped.

y. Overarm separator - It is located above the recoiler mandrel and is used to provide proper winding during rewinding. On over arm separator rubber strips of various thickness are provided, thickness of rubber strips depend on the width of coil.

z. Pusher plate - It helps to push rewound coils to take out from the required mandrel. In-out pusher movement of plate is done by hydraulic cylinder.

\section{Flow chart of pickling line process}

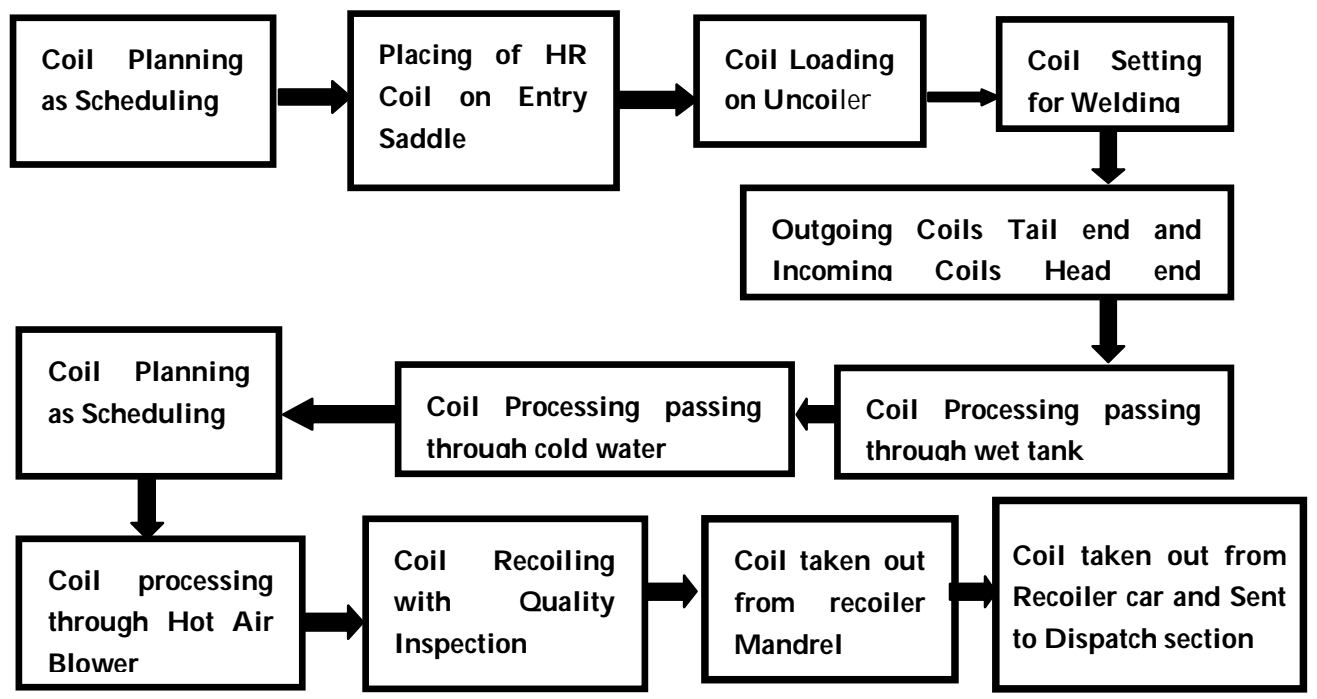


M apana J Sci, 10, 1(2011) Treament of theEffluent Generded from thePidklingMethod

\section{Low temperature favorability}

Pickling of ferrous metals, such as steel strip, tubes or wires, to remove metal oxides $\&$ scales has typically been performed with commercial hydrochloric acid pickle liquor that has been heated to about +200 degrees Fahrenheit by closed circuit steam-acid heat exchangers. A ferrous chloride solution is a principal by product of the pickling process. This high temperatures involved in such roasting processes are disadvantageous for the following reasons:

- Indudes relatively high maintenance \& operating costs for making of these high temperatures.

- In this high temperature organic acid inhibitors typically utilized in acid pickle liquors are largely destroyed.

Therefore to recover iron chloride from the spent pickle liquors have done at very low temperatures.

\section{Recommended management scheme for the well development of the pickling line processing:}

Turbulent acid bath- The pickling tanks are shallow tanks should be made up of granite specially contoured to permit fast $\&$ trouble free threading. The specially arranged flow of acid in the tanks increases the rate of pickling by causing high turbulence of acid in the tank $\&$ thus enabling high speeds with low residence time \& hence less length of the pickling tanks.

Lo-Chlor- The special washing systems after the acid treatment should be provided to ensure that the strips carry very low chlorides which help in prolonging the life of the rolling mill coolant in the subsequent cold rolling operation, apart from ensuring longer self-life of pickled coils.

Environment friendly- The process should consist of special sealing of the tanks \& an efficient fume exhaust \& scrubbing system to ensure no release of acid fumes within the plant \& exhausts stack release of less than $10 \mathrm{mg}$. / $\mathrm{m}^{3}$ of free $\mathrm{HCl}$. Therefore it is conformed to the most stringent air pollution control norms. 
Low consumptions- It ensures maximum utilization of the acid for pickling \& least wastage through effluents, thus resulting into low consumption of acid per ton of production. Effluent recyding of acidic water in the system reduces drastically the consumption of water per ton.

Reduce energy requirements- In order to improve the mechanical breaking of the layer of scale, a stretcher leveler should be installed in front of the chemical treatment section. The newly installed turbulence pickler with flat pickling baths reduces the energy requirements of the continuous pickling line by $20 \%$ \& thus contributes substantially to the saving of resources.

\section{Results}

Effects of $6-18 \%$ of hydrochloric acid $(\mathrm{HCl})$ on workers health at the time of pickling processing

During pickling processing 30 to $33 \%$ of commercial Hydrochloric acid (HCL) is diluted to 6 to $18 \%$ and is prepared favorable for handling and use. Therefore the effects of 6 to $18 \%$ of $\mathrm{HCL}$ on workers health are represented as follows:

\section{Chronic Potential Health Effects:}

- Prolonged or repeated inhalation or ingestion may affect liver, respiration (changes in pulmonary function, chronic bronchitis), teeth (yellowing of teeth and erosion of tooth enamel), kidneys, and behavior.

- Prolonged or repeated skin contact may cause dermatitis.

- Prolonged or repeated eye contact with vapor/ mist may cause conjunctivitis.

- Chronic occupational exposure to hydrochloric acid has been reported to cause gastritis, chronic bronchitis, dermatitis, and photosensitization in workers. Prolonged exposure to low concentrations may also cause dental discoloration and erosion.

- Chronic inhalation exposure caused hyperplasia of the nasal mucosa, larynx, and trachea and lesions in the nasal cavity in rats. 
M apana J Sci, 10, 1(2011) Treamentof theEffluent Generded from thePidklingMethod

\section{Reproductive/D evelopmental Effects:}

- No information is available on the reproductive or developmental effects of hydrochloric acid in humans.

- In rats exposed to hydrochloric acid by inhalation, severe dyspnea, cyanosis, and In rats exposed to hydrochloric acid by inhalation, severe dyspnea, cyanosis, and altered estrus cycles have been reported in dams, and increased fetal mortality and decreased fetal weight have been reported in the offspring.

\section{Cancer Risk:}

- No information is available on the carcinogenic effects of hydrochloric acid in humans.

- In one study, no carcinogenic response was observed in rats exposed via inhalation.

- EPA has not dassified hydrochloric acid with respect to potential carcinogenicity.

\section{Effects of hydrochloric acid ( $\mathrm{HCl}$ ) emitted as effluent during processing before treatment}

During pickling processing the average emition of hydrochloric acid per week is $13.4 \%$. This percentage is not favorable for human health. It affects tremendously on workers health. Hazards of dilute solutions may be reduced, depending upon the concentration.

Inhalation: Corrosive! Inhalation of vapors can cause coughing, choking, inflammation of the nose, throat, and upper respiratory tract, and in severe cases, pulmonary edema, circulatory failure, and death.

Ingestion: Corrosive! Swallowing hydrochloric acid can cause immediate pain and burns of the mouth, throat, esophagus and gastrointestinal tract. May cause nausea, vomiting, and diarrhea, and in severe cases, death.

Skin Contact: Corrosive! Can cause redness, pain, and severe skin burns. Concentrated solutions cause deep ulcers and discolor skin. 
Eye Contact: Corrosive! Vapors are irritating and may cause damage to the eyes. Contact may cause severe burns and permanent eye damage.

Chronic Exposure:Long-term exposure to concentrated vapors may cause erosion of teeth. Long term exposures seldom occur due to the corrosive properties of the acid.

Aggravation of Pre-existing Conditions: Persons with pre-existing skin disorders or eye problems or impaired respiratory function may be more susceptible to the effects of the substance.

According to National Institute for Occupational Safety $\&$ Health (NIOSH) the maximum exposure limit of hydrochloric acid is 330 mg. / lit. for 24 hours as effluent discharge. The average acid \% of the day is shown in the graph no.1.

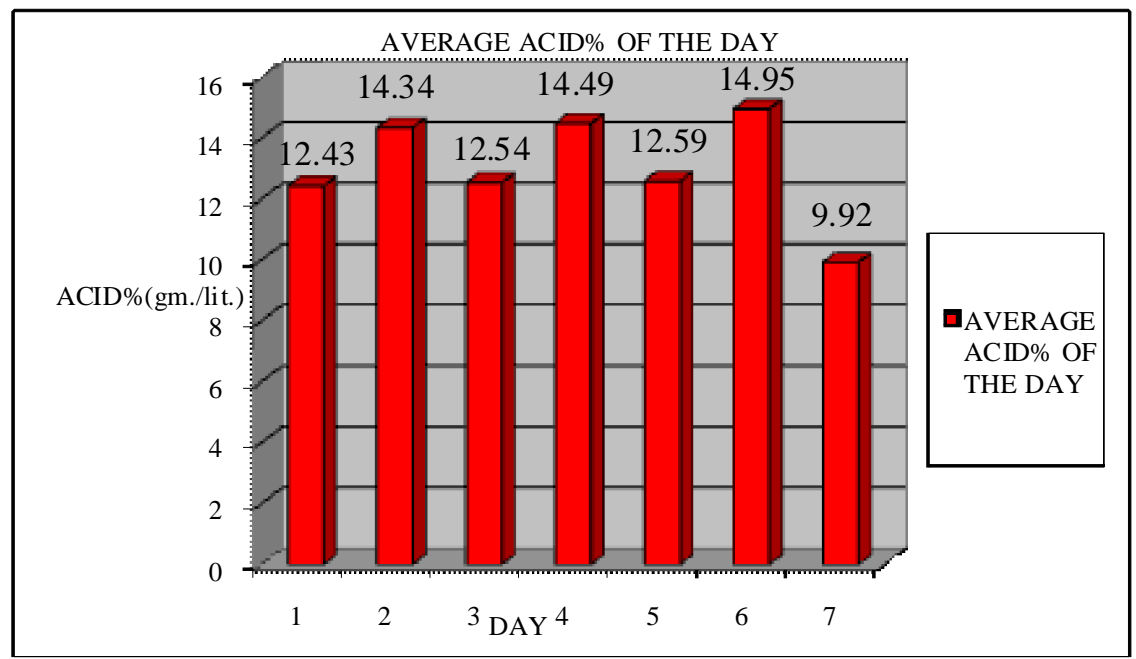

Graph 1: Regular acid\% generated in a week before treatment

According to National Institute for Occupational Safety \& Health (NIOSH) the maximum exposure limit of iron is $10 \mathrm{mg}$. / lit. for 24 hours as effluent discharge. The average ion concentration in a week before treatment is shown in table no. 1 and graph no. 2 
M apana J Sci, 10, 1(2011) Treamentof theEffluent Generded from thePidkling Method

\begin{tabular}{|c|c|c|c|c|c|}
\hline $\begin{array}{l}\text { TOTAL } \\
\text { IRON }\end{array}$ & $\begin{array}{l}\text { TOTAL } \\
\text { IRON }\end{array}$ & $\begin{array}{l}\text { TOTAL } \\
\text { IRON }\end{array}$ & $\begin{array}{l}\text { TOTAL } \\
\text { IRON }\end{array}$ & $\begin{array}{l}\text { AVERAGE } \\
\text { IRON }\end{array}$ & $\begin{array}{c}\text { AVERAGE } \\
\text { IRON }\end{array}$ \\
\hline CONCENTR & CONCENTP & CONCENTR & CONCENTR & CONCENT & CONCENTR \\
\hline ATION AT & ATION AT & ATION AT & ATION AT & RATION & ATION OF \\
\hline 8.00 & 13.00 & 17.00 & 21.00 & OF THE & THE \\
\hline HOUR(g/lit) & HOUR(g/ lit & HOUR(g/lit) & HOUR(g/ lit & DAY ( $g /$ lit) & WEEK ( $g /$ lit) \\
\hline 134.44 & 177.72 & 197.2 & 98.63 & 151.99 & \\
\hline 137.8 & 178.68 & 55.2 & 74.28 & 111.49 & \\
\hline 105.83 & 147.2 & 171.68 & 99.72 & 131.1 & \\
\hline 112.21 & 138.96 & 166.27 & 126.48 & 135.98 & $119.14>01$ \\
\hline 196.72 & 225.6 & 73.11 & 156.8 & 163.05 & \\
\hline 135.12 & 144.38 & 136.77 & 145.32 & 140.39 & \\
\hline 209.83 & 193.92 & 212.28 & 120.73 & 184.18 & \\
\hline
\end{tabular}

Table 1: A verage iron concentration generated in a week before treatment

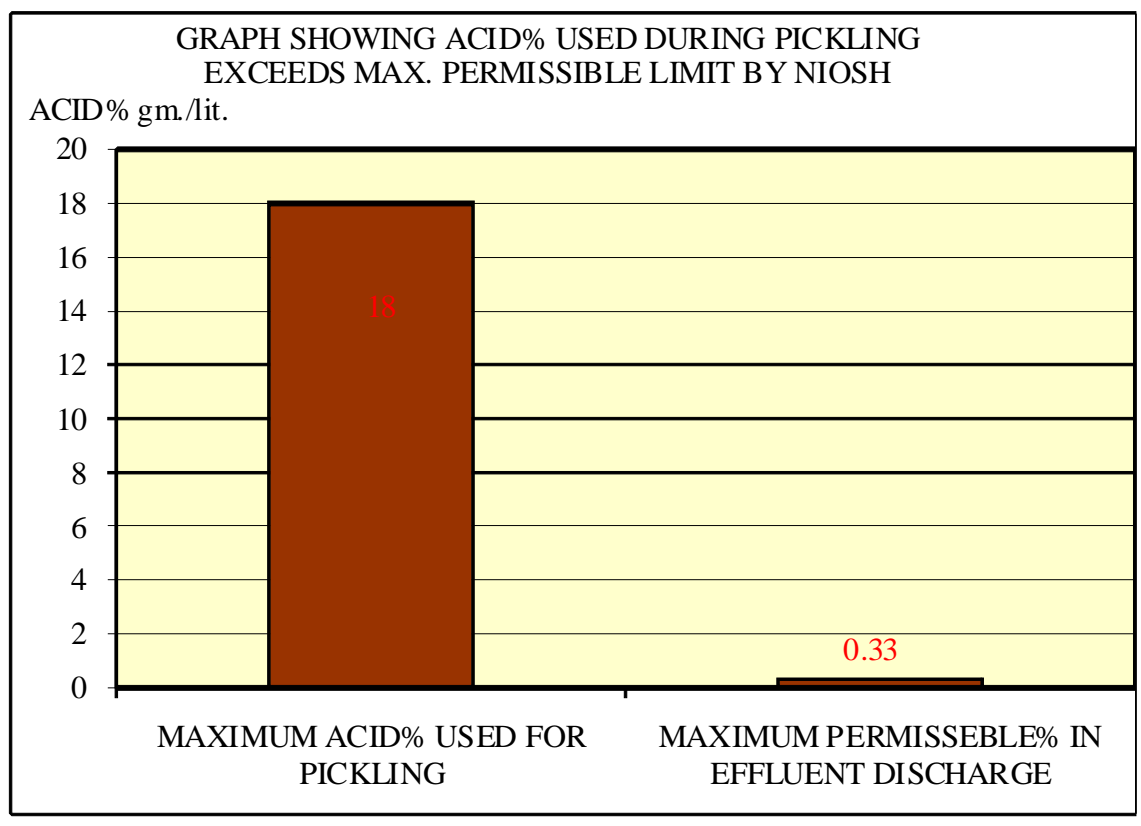

Graph 2: Acid\% used during pickling exceeds max. permissible limit by NOISH 


\section{Effluent treatment process}

During pickling processing several harmful chemical products are generated. Those are highly toxicated to the human health \& environment. Therefore those need an effective treatment, which can remove their toxicating properties in addition to make them ecofriendly. Several steps of the effluent treatment process are discussed as follows:

\section{Emition of discharged slug:}

Chemical reactions of pickling are as follows:

1. $2 \mathrm{Fe}_{2} \mathrm{O}_{3}+8 \mathrm{HCl} \longrightarrow 4 \mathrm{FeCl}_{2}+\mathrm{O}_{2}+4 \mathrm{H}_{2} \mathrm{O}$

2. $\mathrm{Fe}_{2} \mathrm{O}+6 \mathrm{HCl} \longrightarrow 2 \mathrm{FeCl}_{3}+3 \mathrm{H}_{2} \mathrm{O}$

3. $\mathrm{Fe}_{3} \mathrm{O}_{4}+8 \mathrm{HCl} \longrightarrow \mathrm{FeCl}_{2}+2 \mathrm{FeCl}_{3}+4 \mathrm{H}_{2} \mathrm{O}$

4. $\mathrm{FeO}+2 \mathrm{HCl} \longrightarrow \mathrm{FeCl}_{2}+\mathrm{H}_{2} \mathrm{O}$

From the above reactions it is clear that Ferric chloride $\left(\mathrm{FeCl}_{3}\right)$, Ferrous chloride $\left(\mathrm{FeCl}_{2}\right) \&$ Hydrochloric acid $(\mathrm{HCl})$ are the primary products, which are generated during pickling process. Those slugs are liberating out $\&$ stored in N eutralization Tank.

\section{Neutralization:}

Neutralization tank: There are 3 neutralization tanks in the effluent treatment plant. Firstly the discharged slug of acid \& iron are stored in the tanks. One generating pipe is liberated from each tank \& linked to the lime tank1 \& lime tank 2. A pump is attached to each of the generating pipe .So that the slugs from the neutralization tank pumped out to the limetank1 \& lime tank 2

Lime tank 1 \& Lime tank 2: In the lime tanks neutralization reaction takes place, as the result acid neutralized by lime (CaCo3) $\&$ soluble calcium chloride \& carbon-di-oxide is produced. Reactions are as follows:

$$
\begin{aligned}
& \mathrm{CaCO}_{3}+2 \mathrm{HCl} \longrightarrow \mathrm{CaCl}_{2}+\mathrm{CO}_{2}+\mathrm{H}_{2} \mathrm{O} \\
& \mathrm{Ca}(\mathrm{OH})_{2}+2 \mathrm{HCl} \longrightarrow \mathrm{CaCl}_{2}+2 \mathrm{H}_{2} \mathrm{O} \uparrow \\
& 44
\end{aligned}
$$


M apana J Sci, 10, 1(2011) Treament of theEffluent Generded from thePidklingMethod

\section{Clarification:}

Clarifier: After neutralization the slug is entered to clarifier. A darifier is a tank containing some organic chemicals to remove the iron portion of the slug. According to the chemical reactions of the pickling processing it is crystal dear that the iron portion of the slug containing Ferric Chloride $\left(\mathrm{FeCl}_{3}\right)$, Ferrous chloride $\left(\mathrm{FeCl}_{2}\right)$ salts. In the clarifier DOSE POLYMER an effective organic constituent removes these iron salts. After the treatment of D OSE POLYMERS the $\mathrm{pH}$. value is measured by $\mathrm{pH}$. Meter. The value is ranging from $5.5-8.5$ generally.

\section{Slug dry bed formation}

After the treatment by DOSE POLYMER an iron organic compound is produced which is liberated from clarifier \& stored in the slug dry bed.

\section{IRON + DOSE POLYMERS}

\section{IRON POLYMERS}

Reuse of iron slug: In the slug dry bed some heavy organic iron compound is stored which can be utilized in several paint industries to make it an effective reuse On the other hand environment is not damaged due to the reuse of the slug. This means that the industrial process is ecofriendly.

\section{Generation of acid less water}

Ultimately the acid less water is generated. By the pH.Meter it is confirmed that the water is acid less. The $\mathrm{pH}$. is ranging from 5.5 to 8.5 .

\section{Iron generation}

Major part of iron salts is removed by polymerization \& make a slug dry bed but after polymerization the measurement of iron is not taken. But it should need to take appropriate measurement of remaining iron in the ultimate discharged water to make the plant more ecofriendly. Table 1 indicates average iron concentration generated in a week before treatment. 


\section{Reporting}

Previous to effluent treatment there are some reporting measures have taken to the effluents to determine the acidic\% $\&$ iron\% of the slug to remove them with a proper effluent treatment mechanism. Reporting follows the followings:

- Reporting has done at four hours of regular intervals.

- Acid concentration is measured by titration with sodium carbonate $\left(\mathrm{Na}_{2} \mathrm{CO}_{3}\right)$, methyl-orange is used as an indicator.

- Iron $\left(\mathrm{Fe}^{+2}, \mathrm{Fe}^{+3}\right)$ concentration is measured by potassium-dichromate $\left(\mathrm{K}_{2} \mathrm{Cr}_{2} \mathrm{O}_{7}\right)$.

- Specific gravity is measured by hydrometer.

- Temperature is maintained within 50 to $70^{\circ}$ centigrade.

\section{External observations}

Whether the effluent treatment process \& ultimate discharged liquid is eco-friendly or not that is decided by the following external observations:

- The area where the effluent treatment plant is located containing a nice $\&$ clean environment but vegetation is less. The vegetation is consisting of some wild herbs $\&$ shrubs mainly. Trees are not dense in nature. A number of dry \& desiccating trees are there rather than that of healthy well growing trees although the climate is favorable for the growth of the trees, which means that the environment is not fully free from toxic substances.

- There is no vegetation in the ultimate discharged water that means the water is not favorable for the growth of the vegetations.

- The ultimate storage of water is consisting of random $\&$ dense yellow colored precipitations that indicate strong iron depositions.

\section{Long lasting effect}

As the water is stored at ultimate reservoir some of the part is evaporated as water vapor but the major part is entered in the 
aquifer through the soil particles which may results increase in the rate of iron in the ground water $\&$ which ultimately would be cause of any heavy metallic pollution in the human health later in future.

In water solution, variations in $\mathrm{pH}$ value from 7 are mainly due to hydrolysis of salts of strong bases and weak acids or vice versa. The overall $\mathrm{pH}$ range of natural water is generally between 6 and 8 (National Institute for Occupational Safety \& Health) shown in graph no 3.

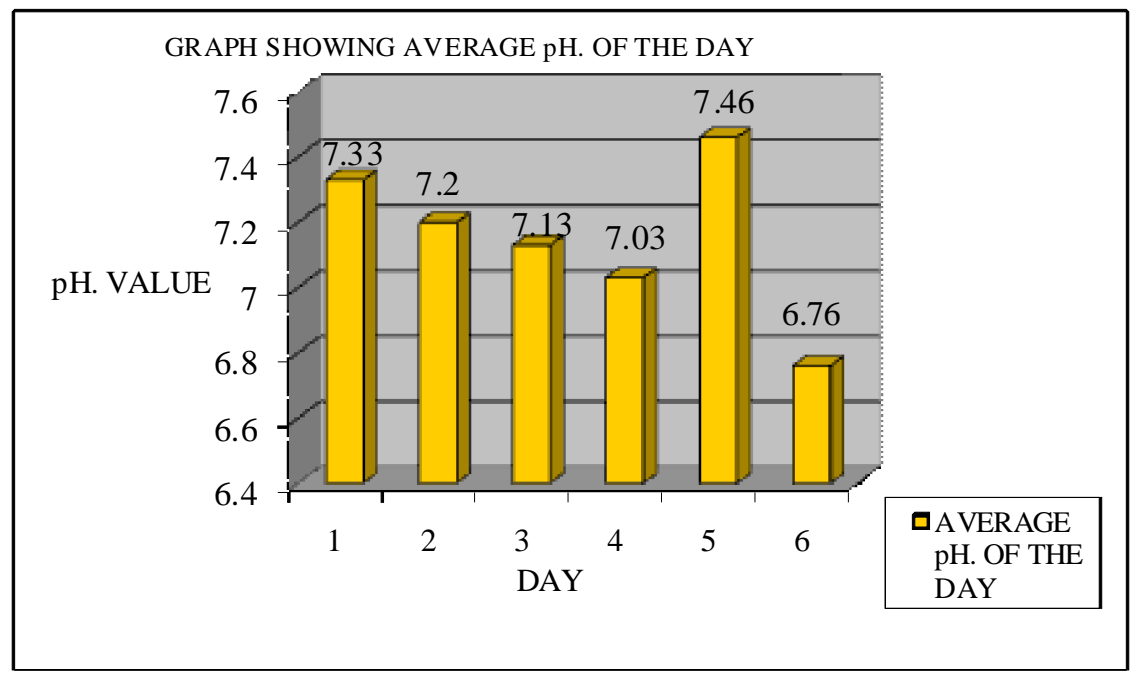

Graph 3: A veragepH of the day

Industrial wastes may be strongly acidic or basic and their effect on $\mathrm{pH}$ value of receiving water depends on the buffering capacity of water .The comparison with $\mathrm{pH}$ of water with neutral $\mathrm{pH}$ after treatment is shown in graph no.4.The graphical representation showing the excess of average $\mathrm{pH}$ in the week than neutral $\mathrm{pH}$ is shown in graph 5

\section{Recommendation protective managements}

\section{Spill M anagement}

If a hydrochloric acid spill or leak occurs, take the following actions:

a) Notify trained personnel immediately, such as the company HAZMAT team or the local fire department. Untrained persons or 
those without proper personal protective equipment must not enter areas with high concentrations of hydrochloric acid.

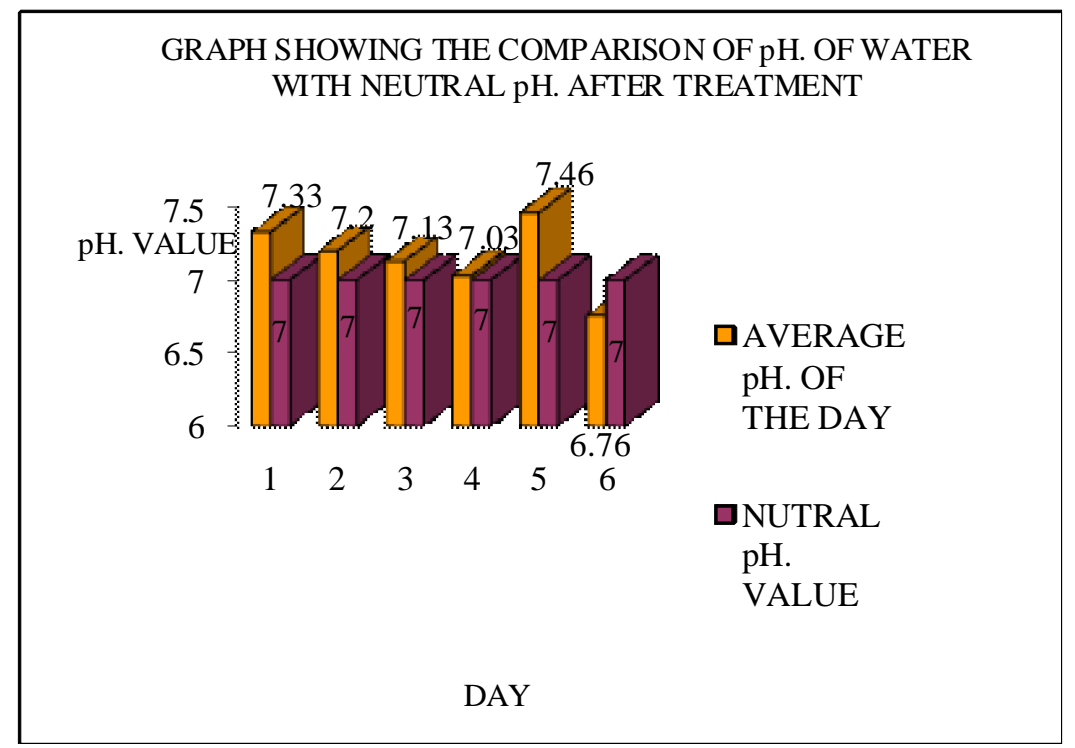

Graph 4: Comparison of $\mathrm{pH}$ of water with neutral $\mathrm{pH}$ after treatment

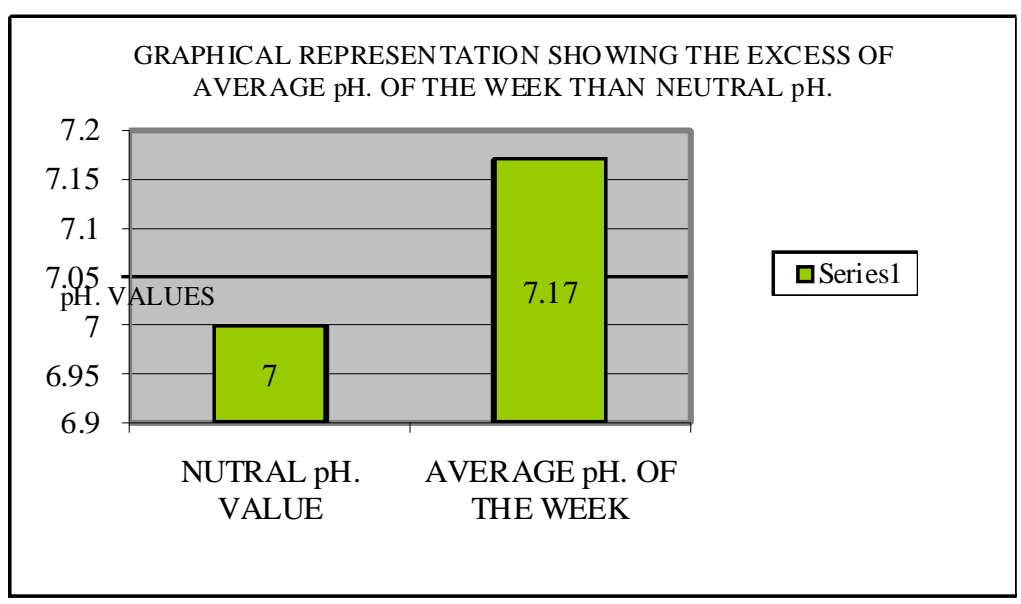

Graph 5: Excess of average pH of theweek than neutral pH.

b) Evacuate and restrict people from the hazardous area of a hydrochloric acid release.

c) Stop or control the source of exposure. If the exposure is from a leaking cylinder, take the cylinder outdoors or to an open area until it has completely drained, and the contents have evaporated. 
d) Ventilate contaminated atmospheres by opening windows to disperse the gas.

e) If the exposure is from the spill of a solution, collect or confine the spilled material. If possible, reclaim the spill material, otherwise dilute and neutralize the spill and dispose in a secured landfill.

f) Refer to the manufacturer's Material Safety Data Sheet (MSDS) for more information about hydrochloric acid hazards.

According to National Institute for Occupational Safety \& Health $(\mathrm{NIOSH})$ the maximum exposure limit of hydrochloric acid is 330 mg. / lit. For 24 hours as effluent discharge.

\section{Recommendation for iron monitoring from ultimate discharged water}

\section{Soldering Iron M onitor V oltage Detection System:}

The Novx M20 is an AC ground monitoring system with audible alarm to detect Iron if the tool tip is properly grounded and has no voltage harmful to sensitive parts. The sensor is located on the tool holder or under the wet wipe sponge, in which the entire conductive sponge becomes the sensor. Tool ground is verified every time the sponge is used. Battery or AC powered and has ground and sensor cable harnesses. System alarm levels can be factory set at either $.25 \mathrm{~V}$ or $1.5 \mathrm{~V}$ (standard).

\section{Recommendation for iron removing method}

\section{Water Iron Removal Unit:}

High content of iron in water causes various problems at consumers end. D efense Research Laboratory (DRL) Tezpur has designed and developed an improved Iron Removal Unit (IRU) to provide clean drinking water for household purposes in moderate cost. The iron removal unit is cylindrical in shape made of mild steel with four chambers and sludge/ backwash outlet valves. An aeration system and double filtration bed have been provided in the unit for efficient functioning.

\section{The steps involved for removal of iron are:}

- Aeration / Gas transfer.

- pH adjustment.

- Oxidation of ferrous into ferric iron. 
- Sedimentation of iron precipitates.

- Double filtration for precipitates.

- Sludge removal from bottom chamber.

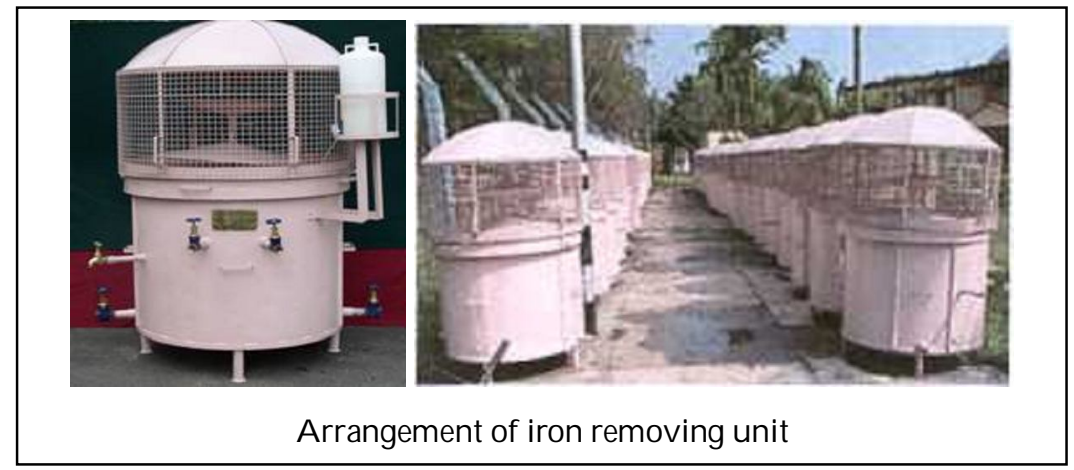

The unit is designed for 300 liters clean water per hour. It is suitable for bringing down the iron content of ferruginous water to World Health Organisation (WHO) standard $(\varangle 0.3 \mathrm{ppm})$ from water having dissolved iron up to $40 \mathrm{mg} / \mathrm{Lt}$.

This iron removal unit can cater to the needs of small size population residing in remote areas where water works does not exist and difficult to install. The unit is useful for Army units, mess, barracks and small communities located in remote areas.

\section{A dvantages of Iron removing unit:}

- Adequate aeration.

- Removal of major portion of iron in the sedimentation chamber.

- Filter bed cracking is prevented and clogging delayed.

- Double filtration ensures better iron removal.

- Proper backwashing.

- Easy operation and maintenance.

\section{D iscussion}

The plant make the effluent treatment very effectively so that the acid $\%$ is diminished $\&$ the $\mathrm{pH}$ value of the ultimate discharged water is measured by $\mathrm{pH}$ meter which shows that it is ranging from 6 to 8 that means the $\mathrm{pH}$ value accepts the permissible limit of National Institute of Safety \& Health (NIOSH). On the other hand the organic constituent Dose Polymers removes the iron part 
but the iron\% is not monitored \& confirmed in the ultimate discharged water. Although from the external observation it is being sure that some yellow iron precipitation is present in this water. Therefore the water has lost its efficiency for reusing. If we make some monitoring $\&$ removing processes of this iron, which is stored in the ultimate discharged water, then it can be used effectively.

Due to the excessive use of water in the industries the water level of the city is reduced day-by-day so we have to take care of the reuse of this large gallon of water, as the cost for this purpose is moderate in nature.

Another important assumption is this water with iron precipitation may enter in the underground aquifer $\&$ then contaminate with the purify drinking water $\&$ ultimately results heavy metallic pollution in human health. Therefore we must be take care to check this contamination by reuse of this water.

\section{Reference}

[1] K. Urano, T. Ase, Y. Nato (1984), Recovery of acid from wastewater by electrodialysis, Desalination 51: 213- 226.

[2] J. Wis'niewski, G. Wis'niewska (1997), Acids and iron salts removal from rinsing water after metal etching, Desalination 109:187-193.

[3] I.Dobrevsky, M. Dimova-Todorova, T. Panayotova (1996), Electroplating rinse waste water treatment by ion exchange, Desalination 108, 277-280.

[4] J. Wis'niewski, S. Suder(1995), Water recovery from etching effluents for the purpose of rinsing stainless steel, Desalination 101: 245-253.

[5] R. Wo' dzki, G. Sionkowski, T. Hudzik-Pieta (1996), Recovery of metal ions from electroplating rinse solutions using Donnan dialysis technique, Pol. J. Environ. Studies 5 (4): 45-50.

[6] A.K. Guha, C.H. Yun, R. Basu, K.K. Sirkar (1994), Heavy metal removal and recovery by contained liquid membrane permeator, Am. Inst. Chem. Eng. J. 40:1223-1236.

[7] K. Scott, Handbook of Industrial Membranes, first ed., Elsevier, Oxford, UK, (1997).

[8] Xijun Chai, Guohua Chen, Po-Lock Yue, Yongli Mi (1997), Pilot scale membrane separation of electroplating wastewater by reverse osmosis, J. M embr. Sci. 123: 235-242. 